\title{
Benefit of varicocelectomy in infertile men with varicocele
}

\section{Shreeharsha Mallappa Awati*}

Department of Urology, Sanjay Gandhi Institute of Trauma and Orthopaedics, Bangalore, Karnataka, India

Received: 07 June 2020

Accepted: 16 June 2020

\section{*Correspondence:}

Dr. Shreeharsha Mallappa Awati,

E-mail: awatism@gmail.com

Copyright: (C) the author(s), publisher and licensee Medip Academy. This is an open-access article distributed under the terms of the Creative Commons Attribution Non-Commercial License, which permits unrestricted non-commercial use, distribution, and reproduction in any medium, provided the original work is properly cited.

\section{ABSTRACT}

Background: Varicocelectomy does improve semen parameters and pregnancy rates in men with infertility. Various studies have shown the extent of benefit and also shown that some may not benefit. It is important to counsel the patients about the same. The present study was done to determine how much varicocelectomy is beneficial to infertile men with varicocele.

Methods: A prospective observational cohort study was conducted on 25 patients undergoing varicocelectomy for infertility at St. John Medical College Hospital, Bangalore from $1^{\text {st }}$ June 2013 to $31^{\text {st }}$ May 2014. Clinical data, semen analysis, scrotal imaging was done and postoperatively semen analysis was done after three months. The data was analysed to find out how much was the benefit of varicocelectomy.

Results: Twenty-five patients underwent varicocelectomy, all of them showed improvement of semen parameters. Fifteen of them had more than $50 \%$ of improvement. This showed that varicocelectomy is beneficial to about $60 \%$ of patients.

Conclusions: Varicocelectomy is beneficial to infertile men with palpable varicocele and abnormal semen parameters.

Keywords: Infertility, Scrotum, Semen, Testis, Varicocele, Varicocelectomy

\section{INTRODUCTION}

An abnormal tortuosity and dilation of the veins of the pampiniform plexus is known as varicocele .Incidence of varicocele (all grades) in the general population of healthy males is $10 \%$ to $15 \% .^{1-4}$ Approximately $30-50 \%$ of males with primary infertility have a varicocele..$^{5-8}$ There is a clear association between varicocele, infertility and testicular growth arrest. ${ }^{9-12}$ Varicocelectomy does improve semen parameters and increase the chances of fertility. ${ }^{13-16}$ Not all patients with varicocele will improve following surgery. ${ }^{16}$ It is important to counsel the patients before surgery about the extent of benefit that is provided by varicocelectomy.

Present study was done to determine how much varicocelectomy is beneficial in the improvement of semen parameters.

\section{METHODS}

Prospective observational cohort study conducted on 25 patients undergoing varicocele surgery for infertility at St. John's Medical College Hospital, Bangalore from $1^{\text {st }}$ June 2013 to $31^{\text {st }}$ May 2014.

\section{Inclusion criteria}

- A male patient presenting with infertility due to varicocele only who gives consent for participating in the study

- An infertile adult, when all of following condition are met:

a. The couple has known infertility (failure to initiate a pregnancy after at least one year of unprotected coitus at a normal frequency with adequate technique) 
b. The female partner has known fertility or a potentially treatable cause of fertility

c. The varicocoele is palpable on physical examination, or if suspected, the varicocoele is corroborated by ultrasound examination

d. The male partner has abnormal semen analysis.

\section{Exclusion criteria}

- Adult fertile men with incidentally detected varicocoele, adolescent varicocoele, persons meeting inclusion criteria but not willing to give informed consent

- Patients using any form of contraception during the study

- Patients who had/have been taking medications for infertility

- Patients who have taken in the past/taking medications which affect semen parameters.

\section{Method of collection of data}

Twenty-five patients were included in the study, all of whom fulfilled protocol requirements. Patients underwent standard evaluation consisting of clinical examination, two semen analyses and scrotal ultrasonography. The following parameters were recorded:

- $\quad$ Age of patient

- Duration of infertility

- History of smoking

- History of drug intake

- Varicocoele laterality

- Grade of varicocoele - diagnostic classification of the WHO-1993
a. Grade I - palpable only during the valsalva maneuver
b. Grade II - palpable without the valsalva maneuver
c. Grade III - visible without palpation,

- Two Semen analysis reports at least 2 months apart mean value was adopted

- Testicular volume (by ultrasonography)

- Pampiniform plexus vein diameter (by ultrasonography).

Twenty-five consecutive cases underwent varicocele surgery (subinguinal approach) for infertility after giving informed consent and fulfilling criteria mentioned above. Patients were advised not to use any form of contraception and abstain from smoking for the duration of the study (as smoking is an independent risk factor for infertility).

The patients were reassessed between 90 and 120 days post-operatively with the following:

- History to confirm that patient is not smoking
- Clinical examination to confirm absence of genital infection

- Two Semen analyses were done - mean value was adopted.

Patients, who had more than 50\% improvement in sperm count postoperatively, as compared to preoperative sperm count, were considered as responders.

\section{Statistical analysis}

Data are presented as means \pm standard deviation (SD) or percentages. All statistical analysis was performed using SPSS V18.0 (SPSS Inc., Chicago, IL).

\section{RESULTS}

Twenty-five patients met the inclusion criteria and underwent subinguinal varicocele ligation and were followed up as per protocol.

Table 1: Age distribution of patients.

\begin{tabular}{|lll|}
\hline Age group & No. of patients $(\mathbf{n}=\mathbf{2 5})$ & Percentage \\
\hline $0-10$ & 0 & \\
\hline $11-20$ & 0 & $40 \%$ \\
\hline $21-30$ & 10 & $56 \%$ \\
\hline $31-40$ & 14 & $04 \%$ \\
\hline $41-50$ & 1 & \\
\hline Mean & 31.92 & \\
\hline SD & 4.78 & \\
\hline
\end{tabular}

Table 2: Duration of infertility.

\begin{tabular}{|lll|}
\hline $\begin{array}{l}\text { Duration of } \\
\text { infertility }\end{array}$ & No. of patients & Percentage \\
\hline 0-5 years & 21 & $84 \%$ \\
\hline 6-10 years & 2 & $08 \%$ \\
\hline 11-15 years & 1 & $04 \%$ \\
\hline 16-20 years & 0 & \\
\hline 21-25 years & 0 & $04 \%$ \\
\hline 25-30 years & 1 & \\
\hline Mean & 4.66 & \\
\hline SD & 5.53 & \\
\hline
\end{tabular}

Table 3: Laterality of varicocele.

\begin{tabular}{|lll|}
\hline $\begin{array}{l}\text { Laterality of } \\
\text { varicocele }\end{array}$ & No. of patients & Percentage \\
\hline Left & 7 & $28 \%$ \\
\hline Bilateral & 18 & $72 \%$ \\
\hline
\end{tabular}

The most frequent age group analysed in this study was between $31-40$ years of age (56\%). Mean age of patients studied was 31.92 years. with a range of 21-46 years of age (Table 1). Twenty-one (84\%) patient had duration of infertility less than 5 year. Mean duration of infertility was 4.66 years with a range of 1 to 28 years (Table 2). 
Eighteen patients $(72 \%)$ had bilateral varicocele while 7 patients $(28 \%)$ had left side varicocele (Table 3$)$. Out of 25 patients only 18 patients had right side varicocele among which 4 patients had grade I varicocele, 14 patients had grade II varicocele and, none of the patient had grade III varicocele. All the patients had left side varicocele among which none had grade I varicocele, 22 patients had grade II varicocele while only 3 patients had grade III varicocele (Table 4 ). On right side maximum testicular volume was $16 \mathrm{ml}$, minimum $7 \mathrm{ml}$, median 11 $\mathrm{ml}$ and mean was $11.12 \pm 2.16 \mathrm{ml}$. While on the left side maximum testicular volume was $14.1 \mathrm{ml}$, minimum $6 \mathrm{ml}$, median $11.2 \mathrm{ml}$ and mean was $10.61 \pm 2.30 \mathrm{ml}$. On right side maximum pampiniform vein diameter was $4 \mathrm{~mm}$; minimum $1.6 \mathrm{~mm}$, median $3.2 \mathrm{~mm}$ and mean was $2.87 \pm 0.80 \mathrm{~mm}$. While on the left side maximum pampiniform vein diameter was $4 \mathrm{~mm}$, minimum 3.3 $\mathrm{mm}$, median $3.7 \mathrm{~mm}$ and mean was $3.65 \pm 0.22 \mathrm{~mm}$.
Table 4: Grades of varicocele.

\begin{tabular}{|lll|}
\hline Grades of varicocele & Right & Left \\
\hline Grade I & 4 & 0 \\
\hline Grade II & 14 & 22 \\
\hline Grade III & 0 & 3 \\
\hline
\end{tabular}

Fifteen patients (60\%) responded to treatment (varicocelectomy) i.e., had more than $50 \%$ improvement in sperm count after surgery, while 10 patients $(40 \%)$ had not responded to treatment (Table 5).

Table 5: Response to varicocelectomy.

\begin{tabular}{|lll|}
\hline Response & No. of patients & Percentage \\
\hline Responders & 15 & $60 \%$ \\
\hline Non-responders & 10 & $40 \%$ \\
\hline
\end{tabular}

Table 6: Change in semen parameters after surgery.

\begin{tabular}{|llll|}
\hline Semen parameters & Preoperative & Postoperative & p-value \\
\hline Sperm counts $\left(\times 10^{6} \mathrm{ml}^{-1}\right)$ & 17.38 & 30.83 & 0.001 \\
\hline Sperm Motility $(\%)(\mathrm{Gr}$. III + IV) & 14.88 & 30.80 & 0.001 \\
\hline
\end{tabular}

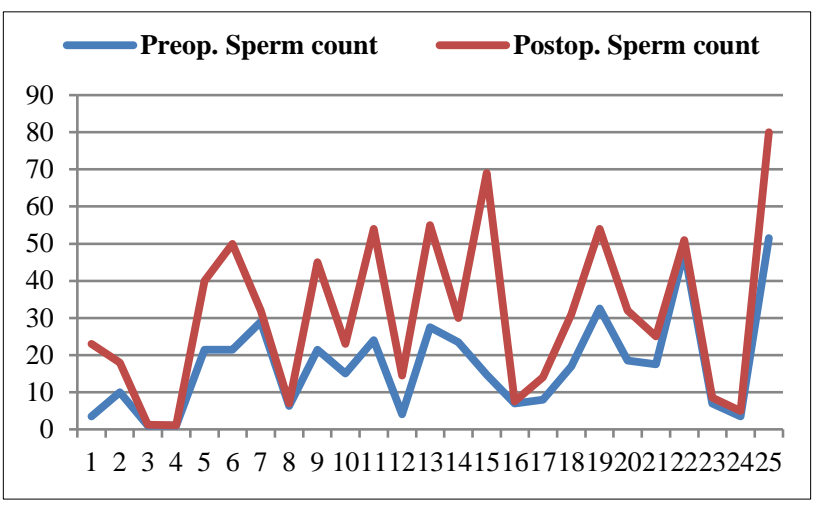

Figure 1: Preoperative and postoperative sperm count.

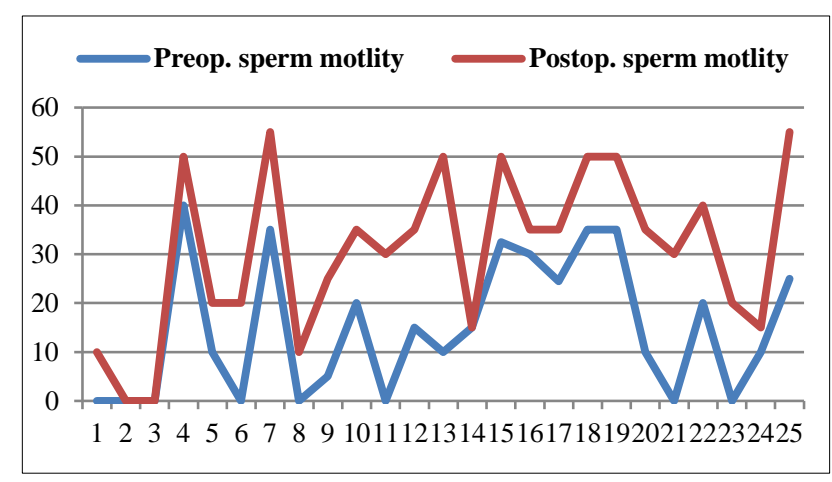

Figure 2: Preoperative and postoperative sperm motility.
Preoperatively maximum sperm count was 51.5 million ml-1, minimum 1 million ml-1, median 17 million ml-1 and mean were $17.38 \pm 13.38$ millions ml-1. While postoperatively maximum sperm count was 80 million ml-1, minimum 1.1 million ml-1, median 30 million ml-1 and mean was 30.83 \pm 21.90 million ml-1 (Table 6) (Figure 1).

Preoperatively maximum sperm motility was 40\%, minimum $0 \%$, median $10 \%$ and mean was $14.88 \pm 13.84 \%$. While postoperatively maximum sperm motility was $55 \%$, minimum $0 \%$, median $35 \%$ and mean was $30.80 \pm 16.87 \%$ (Table 6) (Figure 2).

\section{DISCUSSION}

Varicocelectomy has been reported to improve the semen profile significantly in the majority of patients, and to result in a slight decrease in the frequency of aneuploidy in some chromosomes. ${ }^{17}$ In the present study, after varicocelectomy there is statistically significant improvement in sperm count and motility.

Numerous studies have shown the extent of benefit of varicocelectomy on infertile men.

Osifo OD and Agbugui JO did a 5-year prospective study to examine the effect of varicocelectomy on the fertility profile of affected men. ${ }^{18}$ They did varicocelectomy on 33 men who had infertility, among whom 23 (69.7\%) 
achieved pregnancy over one-year period following surgery. Present study didn’t assess pregnancy rates.

Varicocelectomy improves semen parameters. ${ }^{19}$ Leung L et al, studied impact of varicocelectomy on semen parameters and pregnancy outcomes found improvement in sperm concentration, motility, morphology and pregnancy rates. Cakan $\mathrm{M}$ et al studied impact of varicocelectomy on sperm morphology and found that sperm morphology improves following varicocelectomy. ${ }^{20}$ Senbanjo RO et al, also showed that varicocelectomy results in improvement of semen quality in about $53 \%$ of patients. $^{21}$

Many studies have shown that varicocelectomy results in improvement of many semen parameters viz sperm count, sperm motility, sperm morphology and ultimately pregnancy rates.

Present study has also shown that sperm count and motility improve following varicocelectomy which is statistically significant.

Tung MC et al, studied effect of varicocele on infertility and found that semen parameters improve following varicocelectomy and also found that pain associated with varicocele also subsides. ${ }^{22}$ A retrospective analysis by Pan LJ of 94 varicocele patients showed improvement in sperm concentration and motility. ${ }^{23}$ Magoha GA studied impact of varicocele on infertile men and found improvement in sperm count in $66 \%$ and sperm motility in $6 \%$ of patients. ${ }^{24}$ They also recorded a pregnancy rate of $33.3 \%$.

Yazdani $\mathrm{M}$ et al, studied efficacy of varicocele repair in different age groups. ${ }^{25}$ They divided 83 patients into two groups of less than 30 years and more than 30 years. They found semen parameters improved in both groups and there was no statistically significant difference between two groups regarding efficacy of varicocelectomy. Present study didn't perform such analysis. Jugwirth A et al did analysis of 272 patients undergoing varicocelectomy and found significant improvement in sperm count and motility in all patients. ${ }^{26}$

Shamsa A et al, evaluated four parameters (semen analysis, fertility, early ejaculation and spontaneous abortion among spouses) in relation to varicocele and varicocelectomy during a 13 -year period. ${ }^{27} \mathrm{~A}$ total of 1,711 patients with varicocele underwent varicocelectomy and found that semen parameters improved in about $50 \%$ of patients. They also found significant improvements in fertility, ejaculation and reduction in spontaneous abortion.

Leung $\mathrm{L}$ et al, did a retrospective analysis of 42 patients undergoing varicocelectomy from January 200 to December 2009 and found improvement in sperm concentration, motility and morphology and also improvement in spontaneous pregnancy. ${ }^{28}$
McCullogh A et al, did a study of robot assisted microsurgical varicocelectomy of 145 men with subfertility and found improvements in sperm concentration but not much improvement in motility and morphology. ${ }^{29}$

The present study included analysis of only sperm count and sperm motility. Various studies have analysed sperm morphology, testicular volume and symptom improvement. The ultimate goal of varicocele repair in infertile men is pregnancy. Present study was a short duration study and hence pregnancy rates couldn't be assessed. So large series of studies are needed to assess the true extent of benefit of varicocelectomy. Patients undergoing varicocelectomy need to be followed for long time to assess pregnancy rates.

\section{CONCLUSION}

The present study demonstrated that varicocelectomy significantly improves sperm concentration and motility in infertile men with palpable varicocele and abnormal semen parameters.

\section{ACKNOWLEDGMENTS}

Author would like to thank Dr. Rao AN, professor and head, department of urology, Dr. Mohan A, professor of urology, Dr. Choubey SK, associate professor of urology, St. John's Medical College Hospital and all staff of the department of urology. Authors would also thankful to, Thomas T from St. Johns' Research Institute, for her help and guidance relating to the statistical analysis.

Funding: No funding sources

Conflict of interest: None declared

Ethical approval: The study was approved by the Institutional Ethics Committee

\section{REFERENCES}

1. Lund L, Rasmussen HH, Ernst E. Asymptomatic varicocele testis. Scand J Urol Nephrol. 1993;27(3):395.

2. Niedzielski J, Paduch D, Raczynski P. Assessment of adolescent varicocele. Pediatr Surg Int. 1997;12(56):410.

3. Meacham RB, Townsend RR, Rademacher D, Drose JA. The incidence of varicoceles in the general population when evaluated by physical examination, gray scale sonography and color Doppler sonography. J Urol. 1994;151(6):1535.

4. Di Cataldo A, Trombatore G, Di Carlo I. Idiopathic varicocele: incidence in 517 subjects. Minerva Chir. 1990;45(7):485.

5. Pryor JL, Howards SS. Varicocele. Urol Clin North Am. 1987;14(3):499.

6. Opitz JM, Shapiro SS, Uehling DT. Genetic causes and workup of male and female infertility. Details of 
the clinical evaluation. Postgrad Med. 1979;66(1): 129 .

7. Nashan D, Behre HM, Grunert JH, Nieschlag E. Diagnostic value of scrotal sonography in infertile men: report on 658 cases. Androl. 1990;22(5):387.

8. Jarow JP, Coburn M, Sigman M. Incidence of varicoceles in men with primary and secondary infertility. Urol. 1996;47(1):73.

9. Gorelick JI, Goldstein M. Loss of fertility in men with varicocele. Fertil Steril. 1993;59(3):613.

10. Goldstein M. New insights into the etiology and treatment of male infertility. J Urol. 1997;158(5): 1808 .

11. The influence of varicocele on parameters of fertility in a large group of men presenting to infertility clinics. World Health Organization. Fertil Steril. 1992;57(6):1289.

12. Belloli G, Pesce C, Fantuz E. Varicocele in childhood and adolescence and other testicular anomalies: an epidemiological study. Pediatr Med Chir. 1993;15(2):159.

13. Paduch DA, Niedzielski J. Repair versus observation in adolescent varicocele: a prospective study. J Urol. 1997;158(3):1128.

14. Kass EJ, Reitelman C. Adolescent varicocele. Urol Clin North Am. 1995;2(1):151.

15. Atassi O, Kass EJ, Steinert BW. Testicular growth after successful varicocele correction in adolescents: comparison of artery sparing techniques with the Palomo procedure. J Urol. 1995;153(2):482.

16. Lenzi A, Gandini L, Bagolan P. Sperm parameters after early left varicocele treatment. Fertil Steril. 1998;69(2):347.

17. Acar H, Kilinc M, Guven S, Yurdakul T, Celik R. Comparison of semen profile and frequency of chromosome aneuploidies in sperm nuclei of patients with varicocele before and after varicocelectomy. Andrologia. 2009;41:157-62.

18. Osifo OD, Agbugai JO. Male infertility secondary to varicocele: a study of management of 45 patients. Afr J Reprod Health. 2008;12(1):54-9.

19. Leung L, Ho KL, Tam PC, Yiu MK. Subinguinal microsurgical varicocelectomy for male factor subfertility: ten-year experience. Hong Kong Med J. 2013;19(4):334-40.
20. Cakan M, Bakirtas H, Aldemir M, Demirel F, Altug U. Results of varicocelectomy in patients with isolated teratozoospermia. Urol Int. 2008;80(2):1726.

21. Senbanjo RO, Lawani, Nkposong EO. Changes in seminal quality following varicocelectomy in infertile Nigerian males. Afr J Med Sci. 1996;15(34):63-71.

22. Tung MC, Huang WJ, Chen KK. Modified subinguinal varicocelectomy for painful varicocele and varicocele associated infertility. J Chin Med Assoc. 2004;67(6):296-300.

23. Pan LJ, Pan F, Zhan XY, LiuY, Zhang FL. Treatment of varicocele by microsurgical varicocelectomy: report of 94 cases. Zhonghua Nan Ke Xue. 2012;18(5):416-8.

24. Magoha GA. The role of varicocelectomy in the management of infertile males with varicoceles. East Afr Med J. 1994;71(12):800-2.

25. Yazdani M, Hadi M, Abbasi H, Nourimahdavi K, Khalighinejad P, Mirsattari A, et al. Efficacy of varicocele repair in different age groups. Urol. 2015;86(2):273-5.

26. Jungwirth A, Gogus C, Hauser G, Gomahr A, Schmeller N, Aulitzky W, et al. Clinical outcomes of microsurgical subinguinal varicocelectomy in infertile men. Androl. 2001;33(2):71-4.

27. Shamsa A, Nademi M, Aqaee M, Fard N, Molaei M. Complications and the effect of varicocelectomy on semen analysis, fertility, early ejaculation and spontaneous abortion. Saudi Kidney Dis Transplant. 2010;21(6):1100-5.

28. Leung L, Ho KL, Tam PC, Yiu MK. Subinguinal microsurgical varicocelectomy for male factor sub fertility: ten-year experience. Hong Kong Med J. 2013;19:334-40.

29. McCullough A, Elebyjian L, Ellen J, Mechlin C. A retrospective review of single institution outcomes with robotic assisted microsurical varicocelectomy. Asian J Androl. 2018;20:189-94.

Cite this article as: Awati SM. Benefit of varicocelectomy in infertile men with varicocele. Int J Reprod Contracept Obstet Gynecol 2020;9:270913. 